\title{
PENGEMASAN BUAH DAN SAYUR DENGAN ATMOSFIR TERMODIFIKASI
}

\author{
Erika Pardede \\ Fakultas Pertanian Universitas HKBP Nommensen \\ Email: erikalrp@yahoo.de
}

\begin{abstract}
Being living organs, fresh harvested fruits and vegetables remain metabolically active and undergo ripening and senescence processes. They needs oxygen to stay alive, which is vital for energy production through respiration process. Modified Atmosphere Packaging (MAP) technology utilises in-packaging equilibrium atmosphere, in which the relatively low oxygen and high carbondioxide concentration is achieved naturally inside the package as respiration occurs, which later on leads to a lower respiration rate. Low oxygen concentration could also be achieved by replacing some oxygen with nitrogen and/or application of oxygen scavenger inside in package, thus the respiration rate is reduced and the aging process is retarded. The use of packaging films of correct intermediary permiability to meet a desirable equilibrium modified atmosphere become a key to the succes of MAP. A new technique, so called Perforation-Mediated Modified Atmosphere Packaging (PM-MAP), by having microperforation in the plastic films is applied to correct the exchange of air during storage. Therefore Modified Atmosphere Packaging (MAP) technology offers advantages which leads to extension of the shelf life of fresh produces. Fresh and fresh-cut food industry utilise this advantages to meet the growing demand of convinient and fresh quality fruits and vegetables, in order to maintain freshness quality attributes and to extend the shelf life.
\end{abstract}

Keywords: Modified Atmosphere Packaging, Shelf Life, Fruit, Vegetable, Quality.

\section{PENDAHULUAN}

Modified Atmosphere Packaging (MAP) atau pengemasan dengan atmosfir termodifikasi adalah pengemasan suatu produk di bawah kondisi atmosfir yang sudah dimodifikasi sehingga komposisi gas di dalamnya berbeda dari komposisi udara normal (Jayas and Jeyamkondan, 2002; Mullan and McDowell, 2003). Komposisi gas-gas di udara normal adalah nitrogen $\left(\mathrm{N}_{2}\right) 78,08 \%$, oksigen $\left(\mathrm{O}_{2}\right) 20,95 \%$, karbondioksida $\left(\mathrm{CO}_{2}\right)$ 0,03\%, bersama-sama dengan uap air dan gas-gas inert seperti argon (Lozano, 2006).

Secara alami buah dan sayur yang telah dipanen mengalami proses penuaan dan berakhir dengan pembusukan. Meskipun telah lepas dari tanaman induknya setelah dipanen, buah dan sayuran masih merupakan suatu jaringan yang masih hidup yang masih aktif bermetabolisme. Salah satu reaksi metabolisme yang erat kaitannya dengan mutu dan masa simpan buah dan sayur setelah panen adalah proses respirasi. Selama aktif melakukan respirasi, buah dan sayur memanfaatkan oksigen yang ada di dalam bahan dan di lingkungannya, dan melepas hasil reaksi berupa karbondioksida dan air serta sejumlah energi. Kehadiran oksigen mendorong terjadinya reaksi yang 
berhubungan dengan kerusakan bahan pangan seperti oksidasi lipid, pencoklatan dan oksidasi pigmen. Oksigen juga mendukung pertumbuhan mikroorganisme aerob yang membutuhkan oksigen untuk hidup, tumbuh dan berkembang biak (Soltani et al., 2015).

Kondisi ini lah yang mendasari teknologi modifikasi gas, khususnya oksigen dan karbondioksida pada MAP untuk menekan laju penuaan dan pembusukan. Aplikasi teknologi MAP pada buah dan sayur berfungsi untuk mempertahankan mutu alami sekaligus memperpanjang masa simpan buah dan sayur segar atau produk olahan minimalis buah dan sayur (Mazza and Jayas, 2001; Jayas and Jeyamkondan, 2002; Mullan, and McDowell, 2003.).

$$
\mathrm{nC}_{6} \mathrm{H}_{12} \mathrm{O}_{6}+\mathrm{nO}_{2} \rightarrow \mathrm{nCO}_{2}+\mathrm{nH}_{2} \mathrm{O}+\text { energi }
$$

\section{Gambar 1: Persamaan Reaksi Respirasi}

Selain akibat respirasi, kerusakan buah dan sayur dapat terjadi akibat aktifitas mikroorganisme yang secara alami terbawa dari ladang, atau yang masih tertinggal pada bahan meskipun pencucian telah dilaksanakan, atau pun yang hadir akibat kontaminasi selama penanganan. Pertumbuhan mikroorganisme dapat ditekan dengan penurunan konsentrasi oksigen dan juga kehadiran karbondioksida.

Lebih lanjut lagi, buah dan sayur dapat mengalami kerusakan akibat pelayuan hingga pembusukan oleh adanya penyerapan dan pelepasan uap air dari udara. Secara umum, dengan komposisi gas yang terbentuk dengan MAP, - oksigen rendah dan karbondioksida tinggi -, laju respirasi akan mengalami perlambatan yang mengakibatkan melambatnya proses menuju penuaan dan kebusukan. Sejalan dengan itu umur simpan produk akan mengalami perpanjangan. Dengan demikian MAP menawarkan manfaat ditinjau dari segi mutu, yang terkait dengan masa penyimpanan, pemasaran dan distribusi. MAP dapat antara lain (1) menekan kerusakan pigmen, sehingga mempertahankan kestabilan warna buah dan sayur; (2) menekan laju reaksi pencoklatan khususnya pada buah dan sayuran yang mengalami pemotongan; (3) perbaikan tekstur yang disebabkan oleh aksi karbondioksida pada membran sel; (4) penurunan kerusakan fisiologis yang didorong oleh etilen seperti kerusakan kematian jaringan kulit pada apel dan pir, maupun kerusakan oleh suhu dingin pada buah-buahan yang disimpan pada suhu dingin (Mullan, M. and McDowell, 2003; Wani et al., 2014).

Perbaikan mutu oleh MAP tersebut berdampak pada penurunan kerusakan dan pembusukan komoditi segar, serta berkurangnya penurunan faktor mutu lainnya selama 
penyimpanan, pendistribusian dan pemasaran. Dengan bertambahnya umur kesegaran buah dan sayur, maka jarak daerah yang dapat dijangkau untuk distribusi dan pemasaran pun dapat diperluas. Pengemasan dengan MAP juga menambah tawaran alternatif pilihan bagi konsumen. Dengan demikian ditinjau dari segi ekonomi, teknologi MAP dapat menambah potensi keuntungan pada jalur pemasaran komoditi segar maupun olahan minimalis (Mazza and Jayas, 2001).

\section{PRINSIP DAN METODA MAP}

MAP pada prinsipnya adalah teknik penyimpanan dengan memodifikasi atau merobah komposisi gas di lingkungan sekitar produk untuk tujuan mengurangi laju respirasi, memperlambat pertumbuhan mikroba, dan menghambat kerusakan enzimatik. Modifikasi atau perubahan komposisi udara di lingkungan produk dapat tercapai secara alami ketika produk buah dan sayur ditempatkan dalam kemasan tertutup. Pengurangan oksigen tercapai dengan sendirinya atau spontan yang diakibatkan respirasi komoditi yang menggunakan oksigen yang diikuti dengan naiknya konsentrasi karbondioksida sebagai hasil reaksi respirasi. Teknik demikian dikenal sebagai modifikasi pasif (Caleb et al., 2013). Metoda ini dikenal juga sebagai equilibrium modified atmosphere packaging (EMAP), dimana perubahan atau modifikasi komposisi gas sepenuhnya tergantung pada interaksi laju respirasi dari produk dengan pertukaran gas yang terjadi melalui bahan kemasan, tanpa ada tindakan tertentu terhadap komposisi awal gas (Caner et al., 2008)

Menurut Lozano (2006), respirasi melambat ketika konsentrasi oksigen mulai mencapai $10 \%$, dan perlambatan berlanjut hingga konsentrasi oksigen mencapai $2-4 \%$ untuk kebanyakan jenis buah-buahan. Komposisi gas pada MAP juga menekan produksi etilene pada buah yang menuju ranum, sehingga proses peranuman ikut ditekan. Meskipun demikian menurut Jayas and Jeyamkondan (2002) prekursor untuk etilen terbentuk dan terakumulasi dalam produk, sehingga seketika produk dikembalikan ke kondisi atmosfer normal laju respirasi segera mengalami peningkatan dan mencapai ranum dengan cepat. Dalam hal tersebut MAP dapat menunda proses peranuman.

Metoda modifikasi gas secara aktif dapat dilakukan dengan menggunakan teknik pengurangan dan/atau penambahan gas-gas ke dalam kemasan baik secara langsung maupun tidak langsung. Komposisi gas di dalam kemasan diatur sedemikian 
rupa dimana kandungan oksigen $\left(\mathrm{O}_{2}\right)$ diturunkan di bawah komposisi atmosfer normal, dan menaikkan kandungan gas-gas yang dapat memperlambat laju respirasi seperti karbondioksida $\left(\mathrm{CO}_{2}\right)$ dan karbonmonooksida. Hanya saja penggunaan karbonmonooksida terkendala teknis terkait dengan masalah keamanan mengingat sifatnya yang beracun dan memiliki potensi meledak apabila tidak ditangani dengan hati-hati. (Soltani et al., 2015).

Modifikasi atmosfir yang sudah diformulasikan terlebih dahulu, dimana campuran gas mengandung oksigen yang rendah, menguntungkan untuk produk yang sensitif terhadap oksigen rendah. Dengan metoda ini komposisi gas-gas dapat diatur secara pasti pada taraf yang tidak merusak produk. Komposisi gas ini merupakan hal yang sangat penting dalam penerapan MAP, mengingat setiap jenis produk membutuhkan perbandingan komposisi gas yang spesifik untuk mendapatkan masa simpan yang maksimum. Konsentrasi gas tersebut juga harus mempertimbangkan suhu dan lama penyimpanan yang diinginkan. Semakin tinggi suhu penyimpanan akan mendorong laju respirasi yang semakin tinggi, sehingga pada prakteknya MAP sering dikombinasikan dengan penyimpanan dingin (Lozano, 2006).

Dengan mengeluarkan sebagian udara dalam kemasan dan menggantikannya dengan gas nitrogen $\left(\mathrm{N}_{2}\right)$ akan tercapai suatu kondisi dimana konsentrasi oksigen rendah, sedangkan karbondioksida secara spontan akan naik sejalan dengan reaksi respirasi yang berlangsung. Nitrogen merupakan suatu gas yang relatif tidak reaktif, tidak berbau, tidak berasa dan tidak berwarna. Selain kelarutannya yang rendah dalam air, nitrogen juga bersifat tidak mudah terbakar dan memiliki kerapatan yang lebih kecil dari udara normal.

Teknologi pengemasan aktif menjadi kombinasi yang baik untuk MAP, yakni memodifikasi atmosfir melalui penempatan secara sengaja bahan-bahan pemerangkap atau penyerap gas-gas $\mathrm{O}_{2}$ atau $\mathrm{CO}_{2}$ dalam kemasan (Caleb et al., 2013; Wani et al., 2014). Bahan penyerap oksigen sudah banyak tersedia di pasaran seperti: dithionite, asam askorbat, gas $\mathrm{H}_{2}$ dengan kehadiran paladium, dan oksida besi (FeO). Untuk lebih mengefektifkan tujuan penurunan laju respirasi, dalam kemasan juga dapat ditempatkan bahan penyerap etilen (Brody et al., 2008; Mehyar and Han, 2010).

Kondisi gas dalam sistem MAP bersifat dinamis karena produk buah dan sayur yang masih terus melakukan respirasi yang menggunakan oksigen serta menghasilkan 
karbondioksida, sementara pada saat yang bersamaan juga berlangsung pertukaran gas lewat bahan kemasan. Dengan demikian, kondisi lanjutan setelah bahan dikemas dengan metoda MAP seluruhnya tergantung kepada interaksi gas-gas hasil respirasi produk dengan hasil pertukaran gas-gas dari dan ke luar kemasan (Mattos et al., 2013).

Salah satu faktor yang perlu mendapat perhatian adalah adanya konsentrasi kritikal baik oksigen maupun karbondioksida, yang nilai optimumnya spesifik untuk setiap jenis produk. Kondisi yang melampaui batas toleransi konsentrasi oksigen dan karbondioksida akan mendorong terjadinya respirasi anaerobik menggantikan reaksi normal respirasi aerobik, dimana asam piruvat hasil degradasi glukosa melalui glikolisis, akan memasuki proses fermentasi secara anaerobik untuk mendapatan energi. Menurut Lozano (2006), reaksi anaerobik ini mulai berlangsung ketika konsentrasi oksigen berada di bawah 2-4\%. Proses tersebut menghasilkan senyawa-senyawa alkohol, aldehid dan laktat, yang menyebabkan perkembangan cita-rasa yang tidak baik (off-flavour) yang menurunkan kelayakan untuk dimakan. Selain itu terdapat resiko bertumbuhnya mikroorganisme anaerobik (Jayas and Jeyamkondan, 2002; Lozano, 2006).

Tabel 1: Toleransi Beberapa Buah Dan Sayur Terhadap Oksigen Dan Karbondioksida

\begin{tabular}{|l|l|l|}
\hline Komoditi & $\begin{array}{l}\text { Minimum } \\
\text { Oksigen }\end{array}$ & $\begin{array}{l}\text { Maksimum } \\
\text { Karbondioksida }\end{array}$ \\
\hline Apel & $1-2$ & $0-3$ \\
\hline Kol & $2-3$ & $3-6$ \\
\hline Tomat & $3-5$ & $2-3$ \\
\hline Alpukat & 3 & 5 \\
\hline Pisang & $2-5$ & $2-5$ \\
\hline Kiwi & 2 & 5 \\
\hline Nenas & 5 & 10 \\
\hline Jeruk & $5-10$ & $0-5$ \\
\hline Mangga & $3-7$ & $5-8$ \\
\hline Pepaya & $2-5$ & $5-8$ \\
\hline Brokoli & $1-2$ & $5-10$ \\
\hline
\end{tabular}

Received May 10 ${ }^{\text {th }}$, 2020; Revised June 18 ${ }^{\text {th }}$, 2020; Accepted June 22 ${ }^{\text {th }}$, 2020 


\begin{tabular}{|l|l|l|}
\hline Buncis & $2-3$ & $4-7$ \\
\hline
\end{tabular}

Lozanos (2006) and Mattos et al. (2013)

Di lain pihak, karbondioksida yang dilepaskan oleh produk juga menjadi pertimbangan, dimana buah dan sayur juga memiliki batas toleransi terhadap karbondioksida, seperti halnya terhadap oksigen, meskipun karbondioksida memiliki sifat antimikrobiotik. Sifat antimikrobial dari karbondioksida akan lebih efektif jika dibarengi dengan penyimpanan dingin di bawah suhu $10^{\circ} \mathrm{C}$ jika dibandingkan dengan pada suhu $15^{\circ} \mathrm{C}$ atau di atasnya (Soltani et al., 2015).

Dengan demikian, dalam menjaga dan mempertahankan kondisi yang diinginkan terdapat dua hal yang harus mendapat pertimbangan yakni: laju produksi dan konsumsi gas oleh produk yang dikemas, serta permiabilitas kemasan terhadap gasgas yang terlibat. Laju produksi dan konsumsi gas sebagai akibat reaksi respirasi dipengaruhi oleh faktor-faktor: jenis dan massa komoditi, suhu, tekanan parsial oksigan dan karbondioksida, konsentrasi etilen, dan cahaya. Perpindahan gas melalui difusi melewati kemasan tipis plastik (permiation) dipengaruhi oleh perbedaan konsentrasi. Permiabilitas kemasan terhadap karbon dioksida dan oksigen merupakan faktor utama untuk mendapatkan komposisi atmosfir yang cukup untuk mempertahankan komposisi yang cocok untuk mempertahankan mutu produk yang dikemas (Kartal et al., 2012). Permiabilitas dipengaruhi oleh jenis, ketebalan dan luas area kemasan, termasuk juga oleh suhu, RH, perbedaan konsentrasi oksigen dan karbondioksida dalam kemasan dengan lingkungan luarnya.

\section{PERTIMBANGAN DALAM PENERAPAN}

Selain faktor keunikan setiap komoditi dalam responsnya terhadap kondisi oksigen rendah dan karbondioksida tinggi, dalam aplikasinya pertimbangan lain yang penting adalah penanganan yang higienik dan pemilihan kemasan yang sesuai.

Jenis kemasan yang umum digunakan untuk MAP adalah plastik karena memiliki keunggulan antara lain memiliki sifat sebagai penghalang gas, sangat fleksibel sehingga mudah dibentuk, ringan, dapat direkat dan dicetak. Di samping itu plastik dapat dilapis dengan sesama plastik untuk memperbaiki sifatnya, cukup kuat dan resistan terhadap tekanan fisik selama jalur distribusi, serta menambah estetika produk. Beragam jenis plastik yang umum dipakai dalam MAP, seperti poliolefin, low density

Received May 10 ${ }^{\text {th }}$, 2020; Revised June 18 ${ }^{\text {th }}$, 2020; Accepted June 22 ${ }^{\text {th }}, 2020$ 
polyethylene (LDPE), linear low density polyethylene (LLDPE), high density polyethylene (HDPE), polypropilene (PP), Poliester, polyvinylchloride (PVC), polyvinylidine chloride (PVDC), polyethylene terephthalate (PET), ethylene vinyl alcohol (EVOH), Polyamida (nilon), polyvinyl alcohol (PVOH), ethylene vinyl acetate (EVA) dan polystirene (Soltani et al., 2015)

Dalam pemilihan kemasan plastik, selain karakteristik fisik juga harus memperhatikan sifatnya dimana plastik hendaknya tidak memiliki potensi melepaskan bahan yang berbahaya ketika kontak dengan bahan di dalam kemasan. Selain itu dari segi teknik dan pemasaran, kemasan yang digunakan juga harus memiliki karakter optis yang tansparan dan mengkilat, penggunaan anti kabut pada plastik untuk menghindari uap-uap air yang menghalangi terlihatnya bahan, memiliki kekuatan mekanis untuk menghindari kerusakan akibat tekanan maupun tusukan, memiliki sifat mudah direkat.

Kondisi yang tercipta dalam kemasan dengan atmosfir termodifikasi juga harus dikaitkan dengan potensi perkembangan mikrobia yang dapat merusak buah dan sayur yang dikemas atau yang berbahaya terhadap kesehatan manusia. Secara umum, jenis mikrobia yang mungkin berkembang tergantung pada jenis komoditi yang dikemas. Meningkatnya konsentrasi karbon dioksida yang dibarengi dengan menurunnya oksigen mendorong pertumbuhan bakteri asam laktat oleh kondisi yang memungkinkan terjadinya respirasi anaerob atau fermentasi. Kondisi oksigen yang sangat rendah, 12\%, dapat mendorong pertumbuhan bakteri patogen seperti Clostridium botulinum, Pseudomonas spp., Aspergillus dan Penicilium spp. (Mehyar and Han, 2010). Bakteri lain yang cukup dipertimbangkan dari segi kemanan pangan adalah jenis Listeria monocytogenesis yang bersifat fakultatif anaerob sekaligus psikrotropik (Caleb et al., 2013).

Jayas and Jeyamkondan (2002) mengatakan bahwa berdasarkan pola respirasi yang ditunjukan oleh buah dan sayur yang dikemas dalam kondisi atmosfir termodifikasi, maka diperlukan suatu sistem yang memungkinkan pertukaran gas antara bagian dalam kemasan dengan udara atmosfir di luar kemasan.

\section{Perforasi - Equilibrium Modified Atmosphere Packaging (PM-MAP).}

Kemasan termodifikasi (MAP) kemudian dikembangkan dari Equilibrium Modified Atmosphere Packaging (EMAP) ke Perforasi - Mediated Modified Atmosphere Packaging (PM-MAP). Pada metoda yang terakhir ini, perforasi yang 
sangat halus (micro-perforation) dibuat pada kemasan plastik, yang memungkinkan terjadinya pertukaran atmosfir antara kemasan dan lingkungannya. Sebagai hasilnya adalah adanya karbondioksida yang terlepas ke luar kemasan dan masuknya oksigen ke dalam kemasan. Hal ini memungkinkan terbentuknya kesetimbangan atmosfir secara perlahan dengan masuknya oksigen ke dalam kemasan (Hussein et al., 2015).

Dalam penelitiannya pada buah delima (Punica granatum L.) yang diproses minimal Hussein et al. ${ }^{\mathrm{b}}$ (2015) menemukan bahwa pada kemasan MAP yang tidak diberi perforasi terjadi penurunan oksigen yang sangat progressif dan mencapai titik kritikal pada hari ke-15. Sementara pada kemasan MAP yang diberi perforasi, oksigen meningkat sejalan dengan jumlah perforasi yang dibuat. Akan halnya karbon dioksida, konsentrasi paling tinggi ditemukan pada MAP yang tidak berperforasi. Hal ini menunjukkan bahwa perforasi dapat mencegah terakumulasinya karbon dioksida dan kondensasi uap air pada kemasan. Kemasan berperforasi juga memiliki potensi mencegah pertumbuhan bakteri aerobik mesofilik, yeast dan jamur.

Kartal et al. (2012) mengkombinasikan MAP berperforasi dengan bahan pemerangkap oksigen yang ditempatkan di dalam kemasan strawberry dan menghasilkan masa simpan buah strawberry hingga lebih dari empat minggu. Dibandingkan dengan penelitian sebelumnya oleh Caner et al. (2008) dimana strawberry dikemas secara MAP tanpa perforasi hanya dapat mempertahankan mutu strawberry hanya hingga maksimum 10 hari dengan menggunakan jenis bahan kemasan cast polypropylene (CCP), linear low density polyethylene (LLDPE), dan polyethylene terephthalate $(\mathrm{PET}) /$ ethylene vinyl alcohol $(\mathrm{EVOH}) /$ polyethylene-low-acetyl fraction (LAF) .

\section{PENUTUP}

Industri buah dan sayuran, baik segar maupun fresh cut, memanfaatkan teknologi MAP dan PM-MAP secara besar-besaran, dibarengi dengan penerapan sistem distribusi dingin secara berantai. Kesuksesan penerapan pengemasan dengan modifikasi atmosfir dalam usaha memperpanjang masa simpan buah dan sayur harus disertai oleh penerapan persiapan yang higienis, sanitasi dan penirisan yang baik sebelum pengemasan, serta pencegahan kontaminasi silang.

\section{DAFTAR PUSTAKA}

Received May 10 ${ }^{\text {th }}$, 2020; Revised June 18 ${ }^{\text {th }}$, 2020; Accepted June 22 ${ }^{\text {th }}$, 2020 
Brody, A. L., Bugusu, B., Han, J.H., Sand, C.K. And Mchugh, T.H., 2008, Innovative Food Packaging Solutions, Journal Of Food Science 73(8):R107-R116. DOI: 10.1111/J. 1750.3841.2008.00933X

Caleb, O.J., Mahajan, P.V., Al-Said, F.A. And Opara, U.L. 2013., Modified Atmosphere Packaging Technology Of Fresh And Fresh-Cut Produce And The Microbial Consequences - A Review, Food Bioprocess Technol. 6: 303-329

Caner, C., Aday, M.S. And Demir, M. 2008., Extending The Quality Of Fresh Strawberry By Equilibrium Modified Atmosphere Packaging, Eur. Food Res. Technol. 227:1573-1583

Hussein, Z., Caleb, O.J. And Opara, U.L. ${ }^{A}$ 2015., Perforation-Mediated Modified Atmosphere Packaging Of Fresh And Minimally Processed Produce - A Review, Food Packaging And Shelf Life 6:7-10

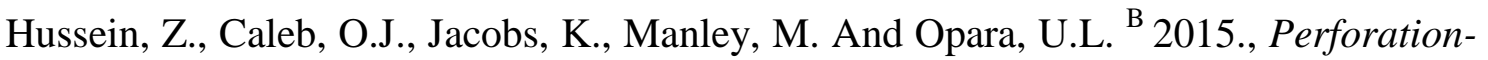
Mediated Modified Atmosphere Packaging And Storage Duration On Physicochemical Properties And Microbiological Quality Of Fresh Minimally Processed "Acco” Pomegranate Arils, Food Science And Technology 64: 911918

Jayas, D.S. And Jeyamkondan, S. 2002., Modified Atmosphere Storage Of Grains Meats Fruits And Vegetables, Biosystems Engineering 82 (3): 235-251

Kartal. S., Aday, M.S. And Caner, C. 2012., Use Of Microperforated Films And Oxygen Scavenger To Maintain Storage Stability Of Fresh Strawberries, Postharvest Biology And Technology 71:32-40

Lozano, J.E. 2006., Fruit Manufacturing: Scientific Basis, Engineering Properties, And Deteriorative Reaction Of Technological Importance, Springer Science + Business Media LLC.

Mazza, G. And Jayas, D.S. 2001., Controlled And Modified Atmosphere Storage, In Eskin, NAM And Robinson, D.S. (Eds,), Food Shelf Life Stability, CRC Press LLC.

Mattos, L.M., Moretti, C.L. And Yosino Da Silva, E.Y. 2013., Effects Of Modified Atmosphere Packaging On Quality Attributes And Physiological Responses Of Fresh-Cut Crisphead Lettuce, Cyta-Journal Of Food, 11(4):329-397, DOI: $10.1080 / 19476337.2013 .777124$ 
Mehyar, G.F. Dan Han, J.H. 2001., Active Packaging For Fresh-Cut Fruits And Vegetables, In Brody, A.L. Zhuang, H. And Han, J.H. (Eds.), Modified Atmosphere Packaging For Fresh-Cut Fruits And Vegetables. Blackwell Publishing Ltd.

Mullan, M. And Mcdowell, D. 2003., Modified Atmosphere Packaging, In Coles, R. Mc. Dowell, D. And Kirwan, M.J. (Eds.), Food Packaging Technology, Blackwell Publishing Ltd.

Soltani, M., Alimardani, R., Mobli, H. And Mohtasebi, S.S. 2015., Modified Atmosphere Packaging Technology For Shelf-Life Extension Of Fruit And Vegetables, Journal Of Applied Packaging Research 7(3): 33-59

Wani, A. A., Singh, P., Gul, K., Wani, M. H. And Langowski, H.C. 2014., Sweet Cherry (Prunus Avium): Critical Factors Affeacting The Composition And Shelf Life, Food Packaging And Shelf Life I:86-99 